\title{
Liaison Activities with the Institute of Physical Chemistry/Russian Academy of Science Fiscal Year 1995
}

\author{
C. H. Delegard
}

Date Published

September 1995

Prepared for the U.S. Department of Energy

Assistant Secretary for Environmental Management

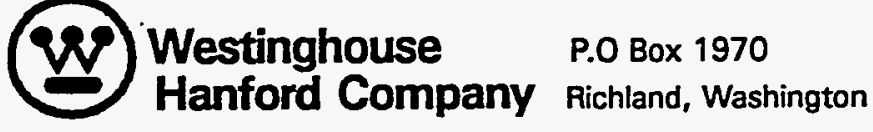

Management and Operations Contractor for the

U.S. Department of Energy under Contract DE-AC06-87RL10930

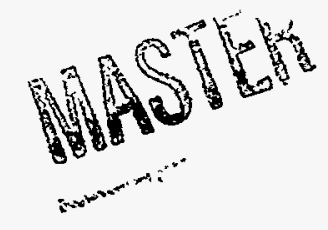

Approved for public release; distribution is unlimited 


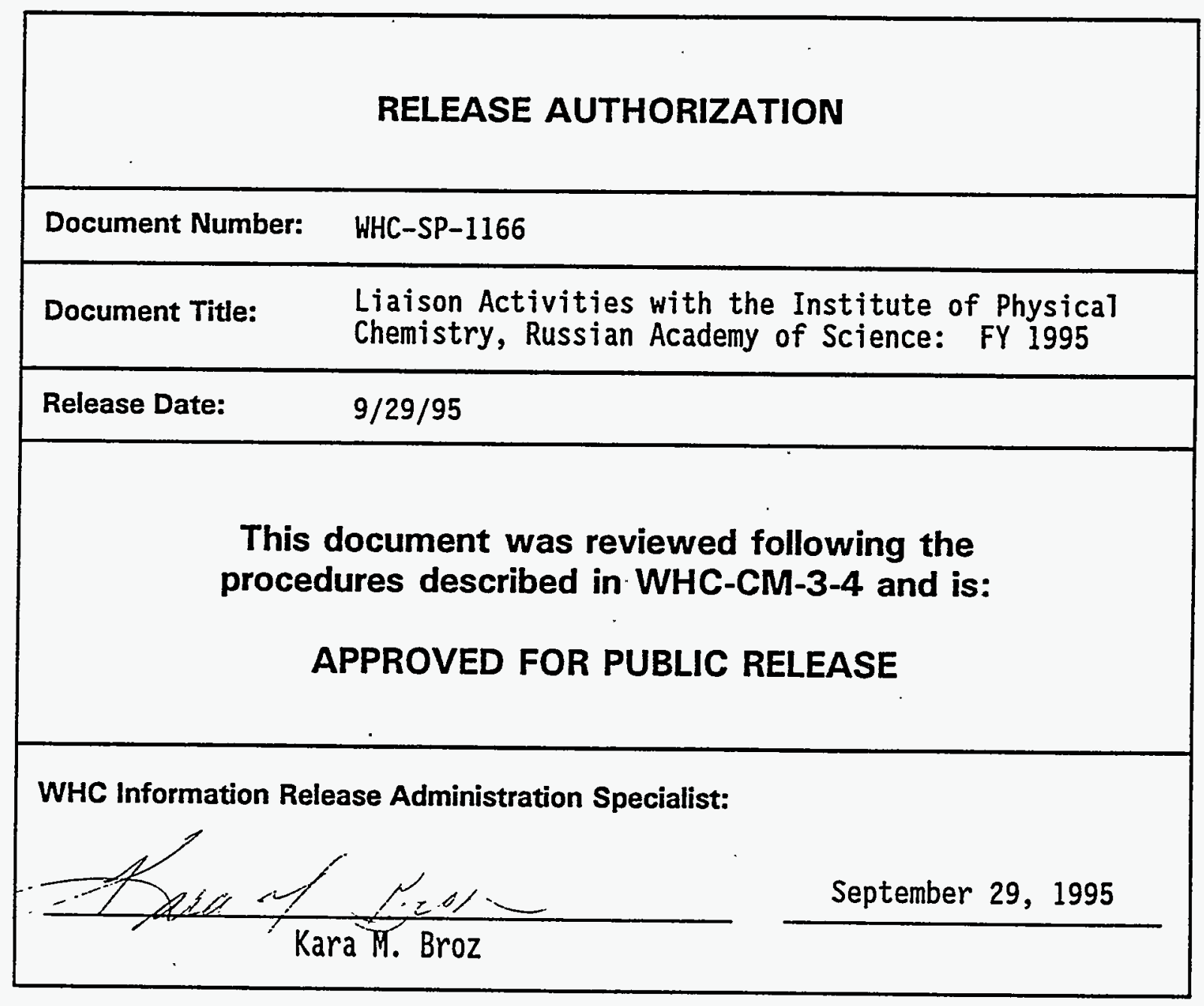




\section{DISCLAIMER}

This report was prepared as an account of work sponsored by an agency of the United States Government. Neither the United States Government nor any agency thereof, nor any of their employees, make any warranty, express or implied, or assumes any legal liability or responsibility for the accuracy, completeness, or usefulness of any information, apparatus, product, or process disclosed, or represents that its use would not infringe privately owned rights. Reference herein to any specific commercial product, process, or service by trade name, trademark, manufacturer, or otherwise does not necessarily constitute or imply its endorsement, recommendation, or favoring by the United States Government or any agency thereof. The views and opinions of authors expressed herein do not necessarily state or reflect those of the United States Government or any agency thereof. 


\section{DISCLAIMER}

Portions of this document may be illegible in electronic image products. Images are produced from the best available original document. 


\title{
LIAISON ACTIVITIES WITH THE INSTITUTE OF PHYSICAL CHEMISTRY/ RUSSIAN ACADEMY OF SCIENCE FISCAL YEAR 1995
}

\begin{abstract}
. EXECUTIVE SUMMARY
Investigations into the chemistry of alkaline Hanford Site tank waste (TTP RL4-3-20-04) were conducted in Fiscal Year 1995 at Westinghouse Hanford Company under the support of the Efficient Separations and Processing Crosscutting Program (EM-53). The investigation had two main subtasks: liaison with the Institute of Physical Chemistry of the Russian Academy of Science and further laboratory testing of the chemistry of thermal reconstitution of Hanford Site tank waste.
\end{abstract}

Progress, which was achieved in the liaison subtask during Fiscal Year 1995, is summarized as follows.

1. A technical dialogue has been established with Institute scientists.

2. Editing was done on a technical literature review on the chemistry of transuranic elements and technetium in alkaline media written by researchers at the Institute. The report was issued in May 1995 as a Westinghouse Hanford Company document. 
3. Four tasks from the Institute were selected for support by the U.S. Department of Energy. Work on three tasks commenced on 1 March 1995; the fourth task commenced on 1 April 1995.

4. Technical information describing the composition of Hanford Site tank waste was supplied to the Institute.

5. A program review of the four tasks was conducted at the Institute during a visit 25 August to 1 September, 1995. A lecture on the origin, composition, and proposed treatment of Hanford Site tank wastes was presented during this visit. Eight additional tasks were proposed by Institute scientists for support in Fiscal Year 1996.

6. A paper was presented at the Fifth International Conference on Radioactive Waste Management and Environmental Remediation (ICEM'95) in Berlin, Germany on 3 to 9 September, 1995 on the solubility of actinides in alkaline media. 


\section{CONTENTS}

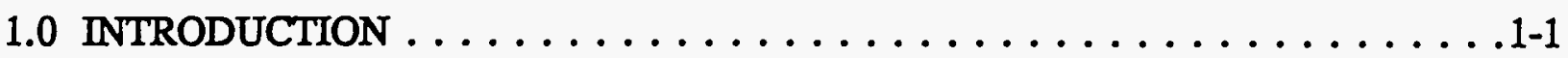

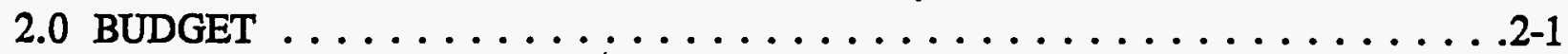

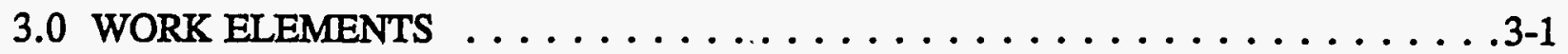

4.0 INSTITUTE OF PHYSICAL CHEMISTRY

/RUSSIAN ACADEMY OF SCIENCE LIAISON ACTIVITIES . . . . . . . . . . . 4-1

4.1 EDITING AND PUBLICATION OF THE LITERATURE REVIEW . . . . 4-1

4.2 TASK SELECTION . . . . . . . . . . . . . . . 4-3

4.3 PROVISION OF TECHNICAL INFORMATION $\ldots \ldots \ldots \ldots \ldots \ldots . . . .44$

4.4 CONSULTATION ON CALCINATION/DISSOLUTION CHEMISTRY . . . 4-7

4.5 TECHNICAL PAPERS . . . . . . . . . . . . . . . 4-7

4.6 TECHNICAL PROGRAM REVIEW $\ldots \ldots \ldots \ldots \ldots \ldots \ldots \ldots$ 4-8

4.6.1 Review of the Solubility Task . . . . . . . . . . . . . 4-8

4.6.2 Review of the Redox Reagents/Reactions Task . . . . . . . . 4-10

4.6.3 Review of the Coprecipitation Task . . . . . . . . . 4-11

4.6.4 Review of the Radiation Chemistry Task . . . . . . . . . . . 4-13

4.6.5 Presentation on Hanford Tank Wastes . . . . . . . . . . . 4-14

4.6.6 Visit to the Waste Processing Facility "Radon" . . . . . . . . 4-15

4.6.7 Provision of a Liquid Scintillation Counter . . . . . . . . . 4-18

4.7 PROPOSED FISCAL YEAR 1996 WORK AT THE

INSTITUTE OF PHYSICAL CHEMISTRY/

RUSSIAN ACADEMY OF SCIENCE . . . . . . . . . . . . . . . . 4-19

5.0 ACKNOWLEDGEMENTS $\ldots \ldots \ldots \ldots \ldots \ldots \ldots \ldots \ldots \ldots \ldots \ldots \ldots$

6.0 REFERENCES $\ldots \ldots \ldots \ldots \ldots \ldots \ldots \ldots \ldots \ldots \ldots \ldots \ldots \ldots \ldots \ldots \ldots$ 


\section{LIST OF TERMS}

C/D calcination/dissolution

DOE U.S. Department of Energy

FY

ICEM fiscal year

Fifth International Conference on Radioactive Waste Management and Environmental Remediation

IPC/RAS

TRU

TTP Institute of Physical Chemistry/Russian Academy of Science Transuranic technical task plan

WHC

Westinghouse Hanford Company 


\subsection{INTRODUCTION}

The task "IPC Liaison and Chemistry of Thermal Reconstitution" is a $\$ 300,000$ program conducted in Fiscal Year (FY) 1995 with the U.S. Department of Energy (DOE) Office of Research and Development (EM-53) Efficient Separations and Processing Crosscutting Program support under TTP RL4-3-20-04. 'The principal investigator is Cal Delegard of the Westinghouse Hanford Company (WHC). The task encompasses two subtasks related to the chemistry of alkaline Hanford Site tank waste:

1. Technical liaison with the Institute of Physical Chemistry, Russian Academy of . Science (IPC/RAS) and their research program into the chemistry of transuranic elements (TRU) and technetium (Tc) in alkaline media.

2. Laboratory investigation of the chemistry of thermal reconstitution (calcination/dissolution or C/D) as an alternative to the present reference Hanford Site tank waste pretreatment flowsheet, Enhanced Sludge Washing.

This report fulfills the milestone "Provide End-of-Year Report on IPC/RAS Liaison," due 30 September 1995 for the liaison subtask. A companion report, fulfilling the milestone to provide an end-of-year report on the C/D activities, also has been prepared (Delegard 1995a). 
WHC-SP-1166

This page intentionally left blank. 


\subsection{BUDGET}

Reallocation of funds to provide more support to the IPC/RAS (specifically, Professor A. K. Pikaev, principal investigator, and his investigations of the role of radiolysis on TRU and Tc chemistry in alkaline media) decreased the total fiscal year funding from $\$ 300,000$ to $\$ 260,000$. To free the funds, tests comparing C/D with enhanced sludge washing were decreased to study three rather than four genuine waste types.

In July 1995, funds spent on chemical and radionuclide analyses for the C/D task were restored by the Tank Waste Characterization Project. The Project restored the funds as a means of supporting process chemistry development tasks, such as $C / D$, being undertaken within the WHC and of making efficient use of analytical laboratory resources which were under-used in the last half of the fiscal year. The funding restoration partially balanced the increased analytical chargeout rates (equivalent to approximately $\$ 63,000$ ) which had been imposed since November 1994 and also permitted additional work scope (on the Cesium Removal Pilot Plant) to be assumed. 
WHC-SP-1166

This page intentionally left blank. 


\subsection{WORK ELEMENTS}

Work elements for the liaison were identified and described in the technical task plan (TTP). Additional work elements, not anticipated at the time of drafting the TTP, emerged during the fiscal year and were incorporated into the task.

The original three work elements for the IPC/RAS liaison include the following.

1. Edit, format, and publish the literature review "Alkaline Chemistry of Transuranium Elements and Technetium and the Treatment of Alkaline Radioactive Wastes" prepared by Professors Peretrukhin, Shilov, and Pikaev.

2. Aid in evaluating and selecting IPC/RAS tasks for DOE support.

3. Provide technical information on the Hanford Site tank waste system to the IPC/RAS.

Additional liaison work elements include the following.

1. Consult with the IPC/RAS scientists on the anticipated chemistry of actinides in $C / D$ processing.

2. Perform a program review at the IPC/RAS and present an overview of Hanford Site tank waste origin and composition.

3. Prepare a technical paper for presentation at the Fifth International Conference on Radioactive Waste Management and Environmental Remediation (ICEM'95), Berlin, Germany, 3 to 9 September 1995. 
WHC-SP-1166

This page intentionally left blank. 


\subsection{LIAISON ACTIVITIES}

The IPC/RAS liaison began in FY 1994 with nominal funding $(\$ 5,000)$ to initiate and continue technical discussions with Professor Vladimir F. Peretrukhin of the IPC/RAS. A large portion of the funding was used to bring Professor Peretrukhin to the Hanford Site (from a conference in San Francisco) in March.1994 for a three-day visit and technical discussions. During his visit, he presented a comprehensive assessment of the current state of knowledge of TRU and Tc chemistry in alkaline media in a one-hour seminar to a group of approximately 80 Hanford Site scientists and engineers. This seminar was a summary of the technical literature review being prepared at the IPC/RAS under DOE sponsorship.

The IPC/RAS delivered their technical literature review on the chemistry of TRU and Tc in alkaline media in August 1994. The IPC/RAS also provided several updated and increasingly detailed lists of proposed areas of investigation of the fundamental and applied chemistry of TRU and Tc in alkaline media for consideration for DOE support beginning in FY 1995.

The initial 11 areas of investigation proposed by the IPC/RAS encompassed 270 person-months of activity. Prioritizing the several proposed tasks began in FY 1994. The DOE international program goal was to select a mix of IPC/RAS tasks that would require approximately $\$ 100,000$ annual support for the first year (equivalent to approximately 10 or 15 person-years of effort at the professorial and doctorate level without Institute overheads) and which would provide the highest immediate value to the Hanford Site and the DOE technical community.

Under the liaison (funded at $\$ 100,000$ in FY 1995), dialogue with the IPC/RAS was conducted almost exclusively by FAX between Cal Delegard, principal investigator, and the lead IPC/RAS principal investigator, Professor Peretrukhin. Transmission of documents was through Federal Express, Dr. Tom Albert (of Tom Albert and Associates, the lead in making business and contract arrangements for the DOE with the IPC/RAS), and other visitors to the IPC/RAS, and the occasional visitor from Russia to the United States (U.S.). Postal service in Russia is not reliable and was not used.

\subsection{EDITING AND PUBLICATION OF THE LITERATURE REVIEW}

In August 1994, the IPC/RAS supplied two paper copies of the technical literature review, "Alkaline Chemistry of Transuranium Elements and Technetium and the Treatment of Alkaline Radioactive Wastes", by way of Dr. Gelis of the IPC/RAS to Dr. Albert. The review, which was written in English, was prepared by Professors Vladimir F. Peretrukhin, Vladimir P. Shilov, and Alexei K. Pikaev. The review contained 192 pages, over 300 references, 7 figures, and 41 tables. Topics addressed in the review were oxidation state thermodynamics, solubilities and speciation, redox reactions, electrochemistry, radiation 
chemistry, and separations (ion exchange, solvent extraction, coprecipitation) of TRU and Tc in alkaline media.

Approximately 15 photocopies of the text were made and distributed to technical persons in the DOE community. In consultation with Dr. Jack Watson, the Program Coordinator of EM-53 International Programs, it was decided, and the Russian authors agreed, that the review would be technically edited and published as a DOE contractor (WHC) document.

The paper text was submitted to the Multimedia Services of WHC (Boeing Computer Services, Richland), optically scanned, and read into electronic format. Because the scanning process mistook the number 0 with the letter 0 ; and was unsuccessful reading superscripts, subscripts, tables, and equations, a multiple iterative sequence of redline corrections and reviews was performed by the principal investigator and Multimedia Services to resolve discrepancies.

At the same time, a technical edit of the paper's contents was performed by the principal investigator. Questions arising in the editing were resolved through a FAX dialogue between the U.S. and Russian principal investigators. Some changes in the punctuation, spelling, and grammar were made, as might be expected. In general, however, the IPC/RAS authors showed outstanding command of the English language as well as clarity in expressing complicated scientific thoughts.

A number of enhancements were made by the principal investigator and Multimedia Services in preparing the report:

- Figures were redrafted and placed in the rest of the document with the WordPerfect 5.1 electronic format. Casting the entire document in electronic format makes it accessible to an electronic database of reports being prepared by DOE.

- A more detailed table of contents was prepared, and indexes of tables and figures were added.

- Technical literature citations were made consistent and expanded to include English translations of reports or books, where available, originally published in Russian.

- A table was prepared listing the titles of the Russian language scientific journals cited in the report, a translation of the journal titles, and a listing of the English language versions of the Russian journals, where available. Significantly, only one reference cited a journal that was not available in English translation.

- Citations of publications written in English were derived for references cited by their versions in the Russian language. 
- The spelling of Russian author names, transliterated into English, were made consistent with the spellings used in the primary chemical science abstracting journal, Chemical Abstracts. This will aid searching of the technical literature for other papers by the same author.

The edited report was dispatched by Federal Express to IPC/RAS authors in mid March, 1995 for review and comment. Comments and changes to the edited report by the authors were received by FAX on 14 April, 1995. Publication and distribution of the final report, Alkaline Chemistry of Transuranium Elements and Technetium and the Treatment of Alkaline Radioactive Wastes, V. F. Peretrukhin, V. P. Shilov, and A. K. Pikaev, WHC-EP-0817, Westinghouse Hanford Company, Richland, Washington (1995), occurred in May 1995.

\subsection{TASK SELECTION}

Nine laboratory tasks into the chemistry of the TRU (neptunium, plutonium, americium; $\mathrm{Np}$, $\mathrm{Pu}$, and $\mathrm{Am}$, respectively) and Tc were proposed by the IPC/RAS for DOE support in March 1994. The proposed tasks, communicated by Professor Peretrukhin during his visit to the Hanford Site, are listed with the requested funding level [in person-months].

1. Determination of hydroxide compound solubility in 1-14 $\mathrm{M} \mathrm{NaOH}$ for Np(IV)-(VI), Pu(III)-(VI), Am(III)-(VI), Tc(IV), Tc(V). [25]

2. Determination of actinide and $\mathrm{Tc}$ species in 1-14 $\mathrm{M} \mathrm{NaOH}$. [10]

3. Research in the field of actinide and Tc redox reactions and the development of techniques for their stabilization in desired oxidation states in alkaline media. [25]

4. Photochemical and sonochemical reactions of actinides in alkaline media and their use to accelerate precipitated hydroxide dissolution. [20]

5. Radiolysis of actinides and Tc in alkaline media. [20]

6. Coprecipitation of actinides (IV), (V), and (VI) from alkaline solutions. [25]

7. Extraction of actinides and Tc from alkaline media; search for new extractants. [20].

8. Sorption of actinides and Tc from alkaline media. [50]

9. Electrochemical methods in alkaline radwaste treatment; actinide and Tc isolation and nitrate, nitrite, and organic compound destruction. [25] 
- Two proposals were added later for consideration.

1. Destruction of organic impurities in waste. [25]

2. Separation of liquid and solid phases in the system $0.1-4 \mathrm{M} \mathrm{NaOH} / \mathrm{Fe}(\mathrm{OH})_{3}$ by filtration with metallic spiral filters. [25].

From May to October 1994, more explicit descriptions of the proposed tasks, as well as references to relevant publications and curriculum vitae of the lead investigators, were provided to the liaison principal investigator by the IPC/RAS. The 11th proposal, related to spiral filters, was withdrawn later when alternative support was obtained from Pacific Northwest Laboratory.

The proposed tasks were broadly classified as fundamental and applied chemistry studies. Tasks related to solubility, speciation, redox reactions, and radiation chemistry address fundamental chemistry; tasks related primarily to separations or processing (filtration, coprecipitation, extraction, electrochemistry, sorption, organic destruction) address applied chemistry.

On the basis of the limited funding (approximately $\$ 100,000$ ) available from the international program, a selection of the tasks had to be made. Consideration was given to the alternatives of supporting a few tasks at full scope or a greater number of tasks at reduced scope. In discussions with Dr. Watson, full support for three or four tasks was selected as the best use of the limited resources.

The decision also was made (in consultation with Dr. Watson and Mr. John Swanson of the Pacific Northwest Laboratory) initially to favor support of fundamental chemistry over applied chemistry. Strong interest was shown in the coprecipitation task, however, because solid-liquid phase separations are the irreducible minimum processes to achieve the low/high-level waste separation in envisioned Hanford Site tank waste pretreatment.

In the end, four tasks were selected for study: solubility, redox reactions, radiation chemistry, and coprecipitation. Outlines of the tasks' scopes, the task principal investigators, and requested support are as follows.

- Determination of solubilities of hydroxo compounds of $\mathrm{Np}$ (IV)-(VI), $\mathrm{Pu}(\mathrm{III})-(\mathrm{VI}), \mathrm{Am}(\mathrm{III})-(\mathrm{VI})$, and Tc(IV)-(V) in 0.5-14 M NaOH. Principal investigator, V. F. Peretrukhin. [25 person-months]

- $\quad$ Determine the solubility of $\mathrm{Np}(\mathrm{IV})$ and $\mathrm{Pu}(\mathrm{IV})$ in reducing media

- Determine the solubility of $\mathrm{Np}(\mathrm{VI})$ and $\mathrm{Pu}(\mathrm{VI})$

- $\quad$ Determine the solubility of $\mathrm{Na}_{2} \mathrm{AnO}_{2}(\mathrm{OH})_{3}(\mathrm{An}=\mathrm{Np}, \mathrm{Pu}, \mathrm{Am})$

- Determine $\mathrm{Am}(\mathrm{OH})_{3}$ solubility (exclude radiolysis products) 
- Study effects of complexing agents (carbonate, phosphate, fluoride, chelating agents, and hydroxycarboxylate anions) on solubilities

- $\quad$ Synthesize and study solubilities of $\mathrm{Tc}(\mathrm{IV})$ and $\mathrm{Tc}(\mathrm{V})$ hydroxides

- Research in An and Tc redox reactions and reagents in alkali. Principal investigator, V. P. Shilov. [25 person-months]

- Study reactions of Np(IV) and Pu(IV) with ozone, atmospheric oxygen, permanganate, persulfate, ferricyanide, ferrate, chromate, hypochlorite, and hypobromite

- Study $\mathrm{Np}(\mathrm{V})$ and $\mathrm{Pu}(\mathrm{V})$ oxidation by atmospheric oxygen in the presence of complexing agents

- Study products of reaction of Tc with hydrazine, hydroxylamine, and sulfite

- Investigate kinetics of $\mathrm{Np}(\mathrm{V}), \mathrm{Pu}(\mathrm{V})$, and $\mathrm{Am}(\mathrm{V})$ reduction by hydrazine, hydroxylamine, and sulfite

- Study Tc(IV)-(V) oxidation by ozone, atmospheric oxygen, manganate, hypochlorite, and hypobromite

- Radiolysis of actinides and technetium in alkaline media. Principal investigator, A. K. Pikaev. [25 person-months]

- Study radiolysis of $N p(V)-(V I)$ and $P u(V)-(V I)$ in alkaline and carbonate media and the effects of nitrite, nitrate, and EDTA

- Study gamma radiolysis oxidation of Tc(IV)-(V) and reduction of Tc(VII) as functions of solution concentrations.

- Determination of coprecipitating agents for An(IV)-(VI). Principal investigator: N. N. Krot. [25 person-months]

- Identify reagents (in addition to permanganate, manganate, ferrate, chromate) as prospective sources of coprecipitants

- $\quad$ Study methods to induce coprecipitation reactions

- Investigate $\mathrm{Np}(\mathrm{V})-(\mathrm{VI})$ and $\mathrm{Pu}(\mathrm{V})-(\mathrm{VI})$ behavior with coprecipitants

- The liaison principal investigator informed the IPC/RAS of this selection in November 1994. However, business arrangements (contracts, avenues for funding, support for Institute facilities) remained to be made by Dr. Albert. Subsequent analysis by the DOE of funding available revealed that only three of the four tasks could be supported. The radiation chemistry task of Professor Pikaev was deleted as a result, and Professor Pikaev was notified by Dr. Albert in February 1995.

Contract negotiations went forward for the remaining three tasks and work at the IPC/RAS commenced on 1 March, 1995 by Professors Peretrukhin, Shilov, and Krot. Monthly reports commenced March 1995 for the three tasks. A request also was received from the three 
researchers for funding to purchase a liquid scintillation counter (estimated cost $\$ 60,000$ to $100,000)$ to perform radionuclide concentration analyses.

In the meantime, reallocation of $\$ 40,000$ of funding from the present TTP (that is, Liaison and Chemistry of Thermal Reconstitution) to the support of the radiation chemistry task was agreed by Dr. Watson and the principal investigator. The $\$ 300,000$ total funds initially allocated for the TTP decreased to $\$ 260,000$. Professor Pikaev was notified in April 1995 by DOE that support for his task was reinstated. Work on this task commenced on 1 April immediately following conclusion of the contract arrangements.

\subsection{PROVISION OF TECHNICAL INFORMATION}

Provision of Hanford Site tank waste technical information continued. Two reports on the chemistry of C/D were sent to the IPC/RAS. These reports, in addition to describing C/D experiments and results, contain general and tank-specific waste compositions that are useful to understanding the existing waste chemistry. The reports delivered were as follows:

- Chemistry of Application of Calcination/Dissolution to the Hanford Tank Waste Inventory, C. H. Delegard, T. D. Elcan, and B. E. Hey, WHC-EP-0766, Westinghouse Hanford Company, Richland, Washington (1994).

- Chemistry of Proposed Calcination/Dissolution Processing of Hanford Site Tank Wastes, C. H. Delegard, WHC-EP-0832, Westinghouse Hanford Company, Richland, Washington (1995).

Reports on the chemistry of technetium, not easily available in Russia, also were provided to the IPC/RAS:

- Zum chemischen Verhalten des Technetiums bei der Behandlung des hochradioaktiven Abfalls, J. Vida, KfK 4642, Kernforschungszentrum Karlsruhe, Karlsruhe, Germany (1989); and its English language translation The Chemical Behavior of Technetium During the Treatment of High-Level Radioactive Waste, translated by James R. Jewett of WHC.

- Valence Effects on Solubility and Sorption: The Solubility of Tc(IV) Oxides, R. E. Meyer, W. D. Arnold, and F. I. Case, NUREG/CR-4303, ORNL-6199, Oak Ridge National Laboratory, Oak Ridge, Tennessee.

- The Solubility of Electrodeposited Tc(IV) Oxides, R. E. Meyer, W. D. Arnold, and F. I. Case, NUREG/CR-4865, ORNL-6374, Oak Ridge National Laboratory, Oak Ridge, Tennessee. 
- Thermodynamic Properties of Tc(TV) Oxides: Solubilities and the Electrode Potential of the Tc(VII)/Tc(IV)-Oxide Couple, R. E. Meyer, W. D. Amold, F. I. Case, and G. D. O'Kelley, NUREG/CR-5108, ORNL-6480, Oak Ridge National Laboratory, Oak Ridge, Tennessee.

- Thermodynamics of Technetium Related to Nuclear Waste.Disposal:

Solubilities of Tc(TV) Oxides and the Electrode Potential of the $T c(V I I) / T c(I V)-O x i d e$ Couple, R. E. Meyer, W. D. Amold, F. I. Case, and G. D. O'Kelley, NUREG/CR-5235, ORNL-6503, Oak Ridge National Laboratory, Oak Ridge, Tennessee.

\subsection{CONSULTATION ON CALCINATTON/DISSOLUTION CHEMISTRY}

Advantage was taken of the knowledge and experience of the IPC/RAS researchers to discuss actinide behavior in the $\mathrm{C} / \mathrm{D}$ processing of plutonium- and neptunium-spiked simulant wastes. The IPC/RAS (specifically, Professor Peretrukhin) evaluated some C/D test results sent by FAX in December 1994. Professor Peretrukhin provided valuable insights into the formation of (V) and (VI) dissolved species and the effects of peroxide complexation in a return FAX message received in January 1995.

\subsection{TECHNICAL PAPERS}

A technical paper on the liaison and the results of the IPC/RAS work funded by the DOE was prepared for presentation at the "Fifth International Conference on Radioactive Waste Management and Environmental Remediation" (ICEM'95), held in Berlin, Germany, on 3 to 9 September 1995. The conference was sponsored by the American Society of Mechanical Engineers, the American Nuclear Society, the DOE, the Kerntechnische Gesellschaft, and the Battelle Memorial Institute. The paper is titled, "Studies of the Chemistry of Transuranium Elements and Technetium at the Institute of Physical Chemistry, Russian Academy of Science."

The paper was prepared at the request of Dr. Teresa Fryberger of the DOE, EM- 53 . Professor Peretrukhin of the IPC/RAS and C. H. Delegard of WHC participated in the conference and presented the paper. The paper has been issued as a WHC document (Peretrukhin and Delegard 1995) and published in the book of proceedings.

The abstract "Solubility of Transuranium Elements and Technetium Hydroxide Compounds in NaOH Solutions in the Presence of Redox and Complexing Agents," by V. F. Peretrukhin, I. G. Tananaev, S. V. Kryutchkov, and V. I. Silin of the IPC/RAS, and C. H. Delegard of WHC, has been submitted for consideration in the symposium "Tank Waste Chemistry" of the Industrial and Engineering Chemistry Division of the American Chemical Society at the Spring 1996 (211th) national meeting of the Society (Peretroukhin et al. 1995b). 


\subsection{TECHNICAL PROGRAM REVIEW}

A technical program review was conducted at the IPC/RAS by C. H. Delegard from 25 August, 1995 to 1 September, 1995 and during the following week while attending the conference ICEM'95 with Professor Peretrukhin. The program review encompassed individual reviews of the four IPC/RAS tasks (on solubility, redox reagents/reactions, coprecipitation, and radiation chemistry); a presentation by C. H. Delegard to staff of the IPC/RAS on Hanford Site tank waste origin, composition, and proposed treatment; and a visit to the radioactive waste research and treatment facility "Radon, " located approximately 80 kilometers outside Moscow near the town of Sergeyev Posad.

\subsubsection{Review of the Solubility Task}

The solubility task was led by Professor Peretrukhin. Also participating in the task and in the related technical discussions were Dr: I. G. Tananaev (who performed actinide compound synthesis and solubility experiments), Dr. V. I. Silin (who investigated the effects of complexing agents and prepared electrodeposited $\mathrm{TcO}_{2}$ ), and Professor S. V. Kryutchkov (who prepared various $\mathrm{Tc}(\mathrm{IV})$ and $\mathrm{Tc}(\mathrm{V})$ hydroxide compounds and investigated their solubilities and complexation). Dr. M. S. Grigoriev performed X-ray diffraction analyses of solids. A draft report, which described the experimentation and results of the solubility task, was presented for early review and comments.

The solubility task review began with a brief overview of the technical literature. Much of this information had been presented in the literature review (Peretrukhin et al. 1995a). Work on the material preparations, oxidation state control, experimental techniques; and results of the solubilities of tetravalent $\mathrm{Pu}$ and $\mathrm{Np}$ hydroxides and sodium double salts of pentavalent $\mathrm{Np}, \mathrm{Pu}$, and $\mathrm{Am}$ were described. Of special concern was the exclusion of oxidation by the oxygen of air in tests with tetravalent actinides (especially for $\mathrm{Np}$ ), clean phase separation (centrifugation versus filtration; they used only centrifugation), attainment of equilibrium; radiolytic reactions (which produce oxidizing or reducing species), and identification of solution species.

For $\mathrm{Np}(\mathrm{IV})$ and $\mathrm{Pu}(\mathrm{IV})$ hydroxides (maintained in their reduced states using $\mathrm{N}_{2} \mathrm{H}_{4}$, hydrazine, as a holding reductant), evidence of amphoteric behavior was manifested by increased solubility as sodium hydroxide concentration. increased from 0.5 to 14 molar. The existence of $\mathrm{Np}(\mathrm{OH})_{5}^{-}$and $\mathrm{Pu}(\mathrm{OH})_{6}^{2-}$ dissolved species was posited based on the data. These are somewhat novel results as little careful work ${ }^{1}$ on the redox-controlled solubility of tetravalent actinides in multi-molar alkaline solutions has been performed.

\footnotetext{
'Work published by Gayer and Leider (Can. J. Chem. 35, pp. 5-7, 1957) on U(IV) solubility in strongly alkaline solution has been called into doubt because lack of strict redox control may have allowed air oxidation to U(VI). Subsequent work has been reported by D. Rai and J. L. Ryan to establish Th(IV), U(IV), and Np(IV) concentrations in alkaline solutions. However, they have not postulated the formation of anionic actinide(IV)-hydroxide complexes.
} 
For the pentavalent actinides ( $\mathrm{Np}, \mathrm{Pu}$, and $\mathrm{Am}$ ), amphoteric behavior again was observed. The results were expected, however, based on earlier studies. The solubility behaviors of the three actinides are similar in magnitude and dependence on hydroxide concentration above 6 molar hydroxide. The formation of the dissolved species $\mathrm{NpO}_{2}(\mathrm{OH})_{4}^{3-}$ above approximately 6 molar hydroxide was proposed based on the solubility behavior.

The suggestion that disproportionation of $\mathrm{Pu}(\mathrm{V})$ occurred in lower concentrations of alkali (that is, below approximately 6 molar) was controversial, however. At these lower $\mathrm{NaOH}$ concentrations, plutonium compound solubility is much lower than the solubilities observed for the comparable pentavalent $\mathrm{Np}$ and Am compounds (whose solubilities remained similar). The postulated $\mathrm{Pu}(\mathrm{V})$ disproportionation is at variance with electrochemical studies performed by Professor Peretrukhin about 20 years ago. Some further tests to substantiate or refute these findings are planned.

Tests to determine the effects of inorganic (carbonate, fluoride, phosphate) and organic (oxalate, glycolate, citrate, and EDTA) complexants on the solubilities of $\mathrm{Np}$ (IV) and $\mathrm{Pu}(\mathrm{IV})$ hydroxides in 1 and 4 molar $\mathrm{NaOH}$ in the presence of hydrazine or sodium dithionite $\left(\mathrm{Na}_{2} \mathrm{~S}_{2} \mathrm{O}_{4}\right)$ holding reductants were described. Nearly all complexing agents were found to increase the solubilities of the tetravalent actinides, although to varying degrees. The effects were lower at higher hydroxide concentration, were greater for $\mathrm{Pu}$ than for $\mathrm{Np}$, and were generally more pronounced for the organic agents, except oxalate, than the inorganic agents.

A brief visit to one of Professor Peretrukhin's laboratories took place. Various compounds and items fabricated from technetium were exhibited in a fume hood: ampoules of $\mathrm{KTcO}_{4}$ (collected at Mayak from a back-extraction step from the U/Pu organic fraction in the first cycle and used as a starting material for subsequent syntheses), $\mathrm{TcO}_{2}, \mathrm{Tc}_{2} \mathrm{~S}_{7}, \mathrm{~K}_{2} \mathrm{TcCl}_{6}$ and other double salts and cluster compounds, a single crystal of Tc metal approximately $5 \mathrm{~mm}$ in diameter and 8 centimeters long prepared by zone refining, some Tc metal foils including one exposed for a year to waters of the Barents Sea, Tc metal wire, various Tc alloys with $\mathrm{Mo}$ and $\mathrm{Ni}$, and a $\mathrm{Tc} / \mathrm{Cu}$ battery. Also shown were electrodeposited and electroplated pieces to be used as electrodes, possible catalysts, or irradiation devices. The laboratory was equipped with furnaces and tools to prepare the various Tc metal shapes.

Professor Peretrukhin described the reluctance of industry to use technetium because of the associated radiation and contamination hazards; applications are practically limited to $\beta$-sources and irradiation devices.

Further discussions then took place on $\mathrm{Tc}(\mathrm{IV})$ and $\mathrm{Tc}(\mathrm{V})$ compound solubility. The various methods used to prepare Tc(IV) and (V) oxide compounds by hydrolysis of double salts, precipitation, washing, and, in some cases, intensive furnace drying, were described. The product compounds were identified by $\mathrm{X}$-ray diffraction.

In most cases, the solubility results were complicated by the facile oxidative dissolution of the starting compound to form pertechnetate $\left(\mathrm{TcO}_{4}^{-}\right)$. Various reductants were tested; only hydrazine was found to be effective (hydroxylamine and sulfite were not) in keeping the oxidative dissolution from occurring. Dissolution kinetics tests bore this out for Tc(IV) and 
$\mathrm{Tc}(\mathrm{V})$. Hydrazine also was found effective in reducing pertechnetate (dithionite and hydroxylamine were not); tests indicated $\mathrm{Tc}(\mathrm{V})$ was formed.

On the basis of the solubility results in the presence of hydrazine, it is believed that hydrazine does not convert the $\mathrm{Tc}(\mathrm{IV})$ to $\mathrm{Tc}(\mathrm{V})$, or $\mathrm{Tc}(\mathrm{V})$ to $\mathrm{Tc}(\mathrm{IV})$. There is some controversy with this result, however, since the solubilities for both experiments are similar and are much higher than expected [approximately 30 increasing to $250 \mu \mathrm{M}$ for Tc(IV) and 35 decreasing to $18 \mu \mathrm{M}$ for $\mathrm{Tc}(\mathrm{V})$ as $\mathrm{NaOH}$ concentration increases from 0.5 to 15 molar]. Colloid formation and oxidation to pertechnetate are two plausible reasons for the high and unexpected solubilities observed especially for $\mathrm{Tc}(\mathrm{IV})$. Further solubility tests were performed using electrodeposited $\mathrm{TcO}_{2}$. The solubilities were lower but, again, the ease of air oxidation was demonstrated.

It was explained that the draft report would benefit scientifically if more experiments and consideration were given. Delay in issuing a final report until December 1995 would help achieve this goal. It was agreed that the draft report could fulfill the terms of the contract and that a more complete final report could be delivered in December as suggested. This arrangement was later accepted by Dr. Jack Watson, the International Program Coordinator.

\subsubsection{Review of the Redox Reagents/Reactions Task}

The actinide and technetium redox reagents and reactions task was led by Professor V. P. Shilov. Because Professor Shilov speaks English with great difficulty, Professor N. N. Krot led the discussions on the work with actinides. Professor Krot also contributed greatly to these studies. Other scientists who worked on the task were present also: Dr. A. Bessonov, Dr. N. Budantseva, and Dr. I. Charushnikova; scientific researcher A. Garnov; engineer V. Prminov; and technician L. Astafurova. Dr. A. Yusov, a prime contributor to this work, was not present.

A three-part technical report on redox reagents and reactions was delivered. The three parts are devoted to $\mathrm{Np}(\mathrm{IV})$ and $\mathrm{Pu}(\mathrm{IV})$ oxidants; pentavalent $\mathrm{Np}, \mathrm{Pu}$, and Am reductants; and $\mathrm{Tc}(\mathrm{IV}, \mathrm{V})$ oxidants and reductants. The report was received in both electronic and paper versions and will be prepared for publication as a WHC document in FY 1996.

The tests with oxidants used freshly precipitated $\mathrm{Np}(\mathrm{IV})$ and $\mathrm{Pu}(\mathrm{IV})$. Oxidants tested included diatomic oxygen, hypochlorite, hypobromite, ozone, persulfate, ferricyanide, permanganate, ferrate $\left(\mathrm{FeO}_{4}^{2-}\right)$, and chromate. All reagents tested, including pure diatomic oxygen and air, oxidized Np(IV) to the (V) or (VI) state. For more powerful oxidants (ozone, persulfate, ferricyanide, and ferrate) and at higher $\mathrm{NaOH}$ concentrations, $\mathrm{Np}(\mathrm{VII})$ could be formed but not until all (V) had been oxidized to (VI). The simultaneous existence of Np(IV), (V), and (VI) also did not occur to a significant extent. Based on these studies, it is likely that neptunium is present in Hanford Site tank wastes as the relatively soluble pentavalent oxidation state. 
Of the reagents studied, only diatomic oxygen and chromate failed to oxidize Pu(IV). Reactions generally were slower and less complete for Pu than for Np. Significantly, the oxidative dissolution of $\mathrm{Pu}(\mathrm{IV})$ by permanganate was incomplete (10 to 60 percent, increasing with $\mathrm{NaOH}$ concentration) and a large fraction of the plutonium reported to the product $\mathrm{MnO}_{2}$ precipitate.

In the second report on redox reagents/reactions, also discussed by Professor Krot, the oxidation of $\mathrm{Np}(\mathrm{V})$ and $\mathrm{Pu}(\mathrm{V})$ by diatomic oxygen was described. Such oxidation was found to occur in concentrations of $\mathrm{NaOH}$ higher than about 6 molar. The report also described tests of reductants for $\mathrm{Np}(\mathrm{V}, \mathrm{VI})$ and $\mathrm{Pu}(\mathrm{V}, \mathrm{VI})$ : dithionite $\left(\mathrm{S}_{2} \mathrm{O}_{4}^{2-}\right)$, sulfite, hydroxylamine, hydrazine, hydroquinone, ascorbate, and thiourea dioxide. The compound $\left(\mathrm{NH}_{2}\right)_{2} \mathrm{C}=\mathrm{SO}_{2}$, thiourea dioxide, is used as a reductant in the textile industry. Professor Krot later described that it also was used with hydrazine to generate U(IV) in nitric acid solution. This technique was in practice in Soviet reprocessing plants before electrolytic reduction of uranium was perfected. Thiourea dioxide is produced by the careful treatment of thiourea with $\mathrm{H}_{2} \mathrm{O}_{2}$ at $0{ }^{\circ} \mathrm{C}$. Of the named reductants, dithionite and hydrazine worked most completely and at the lowest temperature; some heating is required to make other reductants (for example, hydroxylamine and thiourea dioxide) effective.

In the third report on redox reagents/reactions, Dr. Kryutchkov described the work he performed on $\mathrm{Tc}(\mathrm{IV}, \mathrm{V})$ oxidation and $\mathrm{Tc}(\mathrm{VII})$ reduction. The results generally paralleled the solubility results presented with the solubility task and showed the facile air oxidation of the reduced Tc species. The suite of oxidants tested (ozone, permanganate, peroxide, chromate, hypochlorite, and hypobromite) increased this rate.

Conversely, reduction of $\mathrm{Tc}(\mathrm{VII})$ only occurred quantitatively for hydrazine. Other reductants tested were not effective (sulfite) or did not go to completion (hydroxylamine, dithionite). The complexing agent EDTA did not greatly increase or decrease air oxidation of $\mathrm{Tc}(\mathrm{IV})$ or (V).

\subsubsection{Review of the Coprecipitation Task}

The coprecipitation task was led by Professor N. N. Krot. The results of the coprecipitation task were described by Professor Krot with contributions by other scientists active in this task. The other scientists included Professor Shilov, Dr. A. Bessonov, Dr. N. Budantseva, and Dr. I. Charushnikova; scientific researcher A. Garnov; engineer V. Perminov; and technician L. Astafurova.' The final report on this task was presented in electronic and paper versions consisting of two parts: investigation of candidate coprecipitating agents (selection of carriers and optimizing precipitation conditions) and tests with oxidized neptunium and plutonium. Work to publish the coprecipitation task report as a WHC document will commence in FY 1996. 
The coprecipitation "method of appearing reagents" is based on the concept of generating precipitation carriers from species dissolved in the alkaline solution, then inducing the carriers' precipitation by hydrolysis, chemical reduction, or decomposition. The first step in the laboratory program was to investigate key. precipitation reaction parameters (for example, concentration, temperature, $\mathrm{NaOH}$ concentration) for the candidate agents to determine the optimum conditions for their precipitation. The second step was to test the candidate agents with solutions spiked with approximately (1 to 3) $\times 10^{-4}$ molar $\mathrm{Np}(\mathrm{V}, \mathrm{VI})$ and $\mathrm{Pu}(\mathrm{V}, \mathrm{VI})$.

The candidate soluble species, their corresponding precipitated solid phases, and methods used to generate the solid phases are listed:

$\begin{array}{lll}\mathrm{MnO}_{4}^{-}, \mathrm{MnO}_{4}^{2-} & \begin{array}{l}\mathrm{Mn}^{(\mathrm{In})} \mathrm{O}_{2} \\ \mathrm{Mn}^{(\mathrm{m}}(\mathrm{OH})_{2}\end{array} & \begin{array}{l}\text { reduction } \\ \text { reduction }\end{array} \\ \mathrm{FeO} 4_{4}^{2-} & \mathrm{FeOOH}(\mathrm{am}) ? & \text { reduction } \\ \mathrm{Fe}(\mathrm{CN})_{5} \mathrm{NO}^{2-} . & \mathrm{FeOOH}(\mathrm{am}) ? & \text { hydrolysis } \\ \mathrm{CrO}_{4}^{2-} & \mathrm{Cr}(\mathrm{OH})_{3}(\mathrm{am}) & \text { reduction } \\ \mathrm{Cr}\left(\mathrm{CH}_{3} \mathrm{CO}_{2}\right)_{3} & \mathrm{Cr}(\mathrm{OH})_{3}(\mathrm{am}) & \text { hydrolysis } \\ \mathrm{Co}\left(\mathrm{NH}_{3}\right)_{6}^{3+} & \mathrm{Co}(\mathrm{OH})_{2}(\mathrm{am}) & \text { reduction } \\ \mathrm{Co}\left(\mathrm{NH}_{3}\right)_{5} \mathrm{Cl}^{2+} \cdot & \mathrm{Co}(\mathrm{OH})_{2}(\mathrm{am}) & \text { reduction } \\ \mathrm{Co}\left(\mathrm{NH}_{3}\right)_{6}^{3+} & \mathrm{Co}(\mathrm{OH})_{3}(\mathrm{am}) & \text { hydrolysis } \\ \mathrm{Co}\left(\mathrm{NH}_{3}\right)_{5} \mathrm{Cl}^{2+} & \mathrm{Co}(\mathrm{OH})_{3}(\mathrm{am}) & \text { hydrolysis } \\ \mathrm{UO}_{2}\left(\mathrm{O}_{2}\right)_{3}^{4+} & \mathrm{Na} u r a n a t e s & \text { decomposition. }\end{array}$

Professor Krot described the work done for the manganese, iron, chromium, and uranium tests. Dr. Bessonov described the cobalt work.

In general, better precipitation results (kinetics and completeness) were obtained at lower $\mathrm{NaOH}$ concentrations (in the range 0.5 to 14 molar investigated). This was attributed to the amphoterism of many precipitants (particularly divalent manganese and cobalt) and the diffusion and viscosity impediments posed by concentrated $\mathrm{NaOH}$. Higher temperatures (up to $80^{\circ} \mathrm{C}$ ) as expected, favored more rapid precipitation by hydrolysis or by reduction. The IPC researchers were somewhat concerned whether higher temperatures could be obtained in Hanford Site tank waste processing. They were assured that such temperatures were already being considered for alkaline leaching of sludge. 


\section{WHC-SP-1166}

Hydrazine, hydroxylamine, hydrogen peroxide, formate, ascorbate, and sulfite were tested as . reductants for various metals depending on the desired reaction. The possible formation of azide $\left(\mathrm{N}_{3}^{-}\right)$salts from the use of hydrazine was mentioned. Azide salts are known to be sensitive to detonation by shock. Professor Krot said that he expected, but could not confirm, that the product from oxidation of hydrazine would be nitrogen gas. He allowed that azide formation could not be excluded. However, the IPC researchers had made no efforts to identify reductant products in these scouting and optimization tests.

Use of the compound $\left(\mathrm{NH}_{2}\right)_{2} \mathrm{C}=\mathrm{SO}_{2}$, thiourea dioxide, to reduce chromate to $\mathrm{Cr}(\mathrm{OH})_{3}$ also was described. Tests with this compound were pursued in the coprecipitation scouting tests but were not reported; results were reported in the tests of $\mathrm{Np}$ and $\mathrm{Pu}$ redox reactions/reagents led by Professor Shilov.

The coprecipitation tests with $\mathrm{Np}(\mathrm{V}, \mathrm{VI})$ and $\mathrm{Pu}(\mathrm{V}, \mathrm{VI})$ were described. Most precipitating agents (except $\mathrm{MnO}_{2}$ ) were found to be very effective for $\mathrm{Pu}$ coprecipitation. Conversely, coprecipitation results were disappointingly low for $\mathrm{Np}(\mathrm{V}, \mathrm{VI})$ for all agents tested except sodium uranate. These behaviors were thought to be linked with the relative ease of reduction of $\mathrm{Pu}$ to the tetravalent state compared with $\mathrm{Np}$. The $\mathrm{Np}$ apparently remains as pentavalent anionic hydroxide complexes for most reagents and shows increasing hydrolysis as $\mathrm{NaOH}$ concentration increases.

Again, possible disproportionation of $\mathrm{Pu}(\mathrm{V})$ at low concentrations of $\mathrm{NaOH}$ was alluded to based on the ease of reduction of $\mathrm{Pu}(\mathrm{V})$. Studies to resolve the possible disproportionation behavior of $\mathrm{Pu}(\mathrm{V})$ seem to be warranted.

\subsubsection{Review of the Radiation Chemistry Task}

- The radiation chemistry task is being led by Professor A. K. Pikaev. A tour of the radiation chemistry section of the IPC showed the ancient 1930s-era Cockcroft-Walton generator (spoils of war retrieved by the Red Army from Germany) which had been upgraded and maintained in working order until last year, several linear electron accelerators (one of which was being used to sterilize medical equipment) with energies ranging from 1.2 to $12 \mathrm{MeV}$, and two ${ }^{60} \mathrm{Co}$ gamma irradiation facilities. One of the ${ }^{60} \mathrm{Co}$ facilities is being used to irradiate $\mathrm{Np}$ and $\mathrm{Pu}$ solutions in the current radiation chemistry task.

Professor Pikaev described the progress in this task and was joined by Dr. Andrei V. Gogolev, his primary collaborator. Because Dr. Gogolev speaks little English, descriptions of the task were given by Professor Pikaev. In contrast with the other three tasks, which end 30 September, 1995, the contract for this task will end with a report in December 1995. Therefore, no written report, aside from the monthly progress report for the month of July, was provided.

Gamma radiolysis tests have been completed for $\mathrm{Np}(\mathrm{V})$ and $\mathrm{Np}(\mathrm{V})$ in $\mathrm{NaOH}$ solutions (1 to $7 \mathrm{M})$ and in the presence and absence of EDTA, formate, nitrate, and nitrite. Neptunium 
concentrations were approximately $0.3 \mathrm{mM}$. Irradiation of the $\mathrm{NaOH}$ solutions without additives gave about 50 percent reduction of $\mathrm{Np}(\mathrm{VI})$ as determined by visible spectrophotometry. Professor Pikaev postulated that the reduction induced by the radiolytic generation of solvated electrons $\left(e^{-}\right)$and peroxide, which are reducing agents for $N p(V I)$, was opposed by the radiolytic generation of the peroxide radical, $\mathrm{OH} \cdot$, a potent oxidant formed by the interaction of solvated electrons and hydrogen peroxide. The $G$ value of the initial stage of the reduction was about $1 \mathrm{ion} / 100 \mathrm{eV}$.

In the presence of EDTA or formate, $G$ values up to approximately 7 ions $/ 100 \mathrm{eV}$ were observed. Precipitates were formed with both additives. The precipitate formed in the presence of EDTA redissolved readily by itself when irradiation was stopped; the precipitate formed in the presence of formate remained in the solid phase. Dissolution of the precipitate in perchloric acid yielded only $\mathrm{Np}(\mathrm{V})$. Professor Pikaev speculated that the precipitate might be Np(IV) hydroxide which would be readily air oxidized to give Np(V).

Gamma radiolysis of $\mathrm{Np}(\mathrm{VI})$ in the presence of nitrate or nitrite did not affect the $\mathrm{Np}(\mathrm{VI})$ oxidation state. Because of the weak visible spectrum of $\mathrm{Np}(\mathrm{VI})$ in hydroxide media, spectra had to be developed in carbonate media, where absorption bands are stronger. Radiolysis of $\mathrm{Np}(\mathrm{VI})$ in mixed carbonate $(0.67 \mathrm{M})$ and hydroxide $(2.4 \mathrm{M})$ media resulted in a linear reduction of $\mathrm{Np}(\mathrm{VI})$. Initial gamma irradiation tests of $\mathrm{Np}(\mathrm{V})$ showed that oxidation to Np(VI) occurred.

Further tests with plutonium must be conducted before the planned completion of the gamma radiation chemistry task in December 1995.

\subsubsection{Presentation on Hanford Tank Wastes}

A presentation, "Origin, Composition, and Treatment of Hanford Site Tank Wastes," was given to about 30 interested staff members of the IPC/RAS on 30 August 1995. The presentation began with a brief history of the establishment and operation of the Hanford Site, a summary of the various reprocessing and waste processing operations conducted in the Site's production years (1944 to 1990), summary statistics of waste volumes and compositions, and numerous pictures of Hanford Site facilities (reprocessing plants, waste processing facilities such as B plant, the vacuum evaporators and the single- and double-shell tanks).

The formal presentation was followed by a more directed discussion on the chemistry of Hanford Site tank waste. Hand drawn transparencies were presented on the general compositions of tank waste solutions (components and concentration ranges), salt cakes (older salt cakes high in nitrate and phosphate salts and more recent salt cakes dominated by $\mathrm{NaNO}_{3}$ ) and sludge (listing phases such as gibbsite, cancrinite, sodium uranate identified by $\mathrm{X}$-ray diffraction; and postulated, for example, $\mathrm{Cr}(\mathrm{OH})_{3}(\mathrm{am})$ ). Also discussed were organic complexing agents and their effects on tank waste storage and safety. Effects of complexing agents include their complexation of radionuclides, particularly ${ }^{90} \mathrm{Sr}$ and ${ }^{241} \mathrm{Am}$; their 
chemical decomposition in waste conditions such as in tank 101-SY to produce flammable gas; and their possible rapid decomposition at high temperature with oxidation by nitrate.

The history, phenomena, chemistry, and remediation of the tank 101-SY gas generation cycle were also explained in some detail. Particular reference-was made to the work conducted at the Hanford Site and at the Georgia Institute of Technology to clarify the chemistry. Organic decomposition products found in the tank waste wère identified.

Detail on the planned waste processing (pretreatment) was described by discussing the pretreatment block diagram. The following topics were addressed:

- Use of double-shell tanks as processing and storage vessels

- Envisioned fractionation to low- and high-level streams

- Planned removal of ${ }^{137} \mathrm{Cs}$ and the possible adjunct removals of ${ }^{99} \mathrm{Tc},{ }^{90} \mathrm{Sr}$, and TRU from the waste solutions

- Possible requirement to destroy organics in the solution and solid phases

- Possible implementation of chemical recycle and thermal treatments (such as calcination) to obtain sodium hydroxide

- $\quad$ Possible acid-side processing

- Waste solution evaporation.

About 15 copies of the presentation materials (Delegard 1995c) were distributed to the IPC/RAS staff working most closely on the four DOE-funded tasks.

\subsubsection{Visit to the Waste Processing Facility "Radon"}

The visit to the plant "Radon" (located approximately $20 \mathrm{~km}$ outside Sergeyev Posad and approximately $80 \mathrm{~km}$ from Moscow) occurred on 31 August, 1995. The visit was conducted by Dr. Sergey Stefanovsky, the Deputy Director of the Research Center associated with the plant. Facilities visited included the compaction plant, the bituminization plant (soon to be decommissioned), the cementation plant, and a vitrification plant which is currently undergoing cold commissioning.

The "Radon" complex receives many types of radioactive wastes from the Moscow region (contaminated solutions, hardware, papers, containers, air filters, laboratory animal carcasses, radioactive sources, and wastes from the Kurchatov Institute's research reactor) and processes them into immobile forms for burial in belowgrade concrete vaults and cylinders. "Radon" is doing work on cleaning up contaminated soils and also is responsible for providing radioactivity monitoring in the Moscow region thereby receiving support from the district government.

Immobilization media include bitumen (no longer used), a flyash- and clay-bearing cement seemingly similar to Hanford Site grout, a variety of glass formulations (including high phosphate glass and glass without borate fluxing agents), types of Synroc (a composite of 
about four crystalline mineral forms including perovskite and zircon) developed in collaboration with ANSTO (the Australian Nuclear Science and Technology Organization), simple compaction, and, for high-dose metallic radiation sources (for example, ${ }^{60} \mathrm{Co}$ ), casting in a lead-tin alloy. Evaporation, crushing, and incineration waste pretreatment steps also are conducted at "Radon" as well as glass and ceramic technology research and development.

A cold crucible induction melter invented and developed at "Radon" was touted as possibly being of interest to Hanford Site vitrification. The cold crucible is a closely-spaced array of tubing with a alumina-chromia-phosphate refractory cast between the tubing. Water circulating through the tubing cools the shell of the cold crucible. The glass feed is melted by induction, while the cooling on the crucible wall causes a frozen layer of glass to develop which protects the crucible from being attacked by the molten glass.

Much of the waste being vitrified by "Radon" in the cold crucible contains high concentrations of sodium nitrate and thus is similar in composition to Hanford Site tank waste. The "Radon" sodium nitrate waste is only $\mathrm{pH} 8$ to 10 as opposed to $\mathrm{pH} 10$ and higher Hanford Site tank waste. Thermal decomposition of the sodium nitrate in the presence of water will, nevertheless, result in a sodium hydroxide product. The sodium nitrate solutions are concentrated by boiling to approximately 1,000 grams sodium nitrate per liter concentration (that is, a slurry). The slurry is then blended with bentonite clay, and it is the paste that is introduced to the glass melters, not the waste slurry itself.

Dr. Stefanovsky provided a number of papers on the technologies developed at "Radon" during a later meeting at the ICEM'95 conference in Berlin:

- "Vitrification of Intermediate Level Radioactive Waste by Induction Heating," by I. A. Sobolev, S. A. Dmitriyev, F. Y. Lifanov, S. V. Stefanovsky, A. P. Kobelev, V. I. Kornev, O. A. Knyazev, and O. N. Tsveshko, for presentation at ICEM'95, Berlin, (3 to 9 September, 1995).

- $\quad$ Low- and Intermediate-Level Waste Vitrification: Basic Principles, Process Units and Product Characterization;" by I. A. Sobolev., S. A. Dmitriev, F. A. Lifanov, S. V. Stefanovsky, and A. P. Kobolev, for presentation at ICEM'95, Berlin, (3 to 9 September, 1995).

- $\quad$ "Production of Synroc through Melting in 'Cold Crucible'," by F. A. Lifanov, I. A. Sobolev, S. V. Stefanovsky, and D. B. Lopukh, for presentation at ICEM'95, Berlin, (3 to 9 September 1995).

- $\quad$ "Research and Development of Advanced Technologies of Radioactive Waste Treatment," by V. L. Meltser, L. F. Rozdyalovskaya, S. A. Dmitriev, and S. V. Stefanovsky, for presentation at ICEM'95, Berlin, (3 to 9 September, 1995). 
- $\quad$ "EPR of Radiation Centers in Ion-Implanted Glasses Simulating Vitrified Radioactive Wastes," by L. D. Bogomolova, Yu. G. Teplyakov, S. V. Stefanovsky, and S. A. Dmitriev, for presentation at ICEM'95, Berlin, (3 to 9 September, 1995).

- "Volatilization of Radionuclides in Plasmochemical Processing of Radioactive Waste," by S. A. Dmitriev, I. A. Knyazev, S. V. Stefanovsky, and F. A. Lifanov, Physics and Chemistry of Materials Treatment 27(4), pp 377-382 (1993).

- $\quad$ Behavior of Cesium in High-Temperature Processing of Solid Radioactive Waste," by I. A. Knyazev, I. D. Tolstov, and S. V. Stefanovsky, Physics and Chemistry of Materials Treatment 26(6), pp 671-674 (1992).

- $\quad$ "Properties of Fused Slag in Thermal Processing Radioactive Waste in a Blast Furnace," by S. A. Dmitriev, S. V. Stefanovsky, F. A. Lifanov, and I. A. Knyazev, Physics and Chemistry of Materials Treatment 26(1), pp 53-55 (1992).

- "Vitrification of Radioactive Waste in a Plasma Reactor," by S. V. Stefanovsky, I. A. Knyazev, and S. A. Dmitriev, Physics and Chemistry of Materials Treatment 25(4), pp 386-393 (1991).

- $\quad$ "The Structure of Aluminoborosilicate, Borosilicophosphate, and Aluminoborosilicophosphate Vitreous Materials Simulating Vitrified Radioactive Wastes," by L. D. Bogomolova, I. A. Ivanov, S. V. Stefanovsky, Yu. G. Teplyakov, and O. A. Trul, Glass Physics and Chemistry 19(5), pp 413-420 (1993).

- "Water Resistance and Ion Diffusion in Glass Materials Simulating Vitrified Radioactive Waste," by I. A. Ivanov, S. V. Stefanovsky, and A. N. Gulin, Glass Physics and Chemistry 19(5), pp 392-397 (1993).

- $\quad$ "ESR and IR Spectroscopic Studies of Sodium and Aluminosilicophosphate Glasses," L. D. Bogomolova, T. K. Pavlushkina, S. V. Stefanovsky, Yu. G. Teplyakov, and O. A. Trul, Glass Physics and Chemistry 19(3), . pp 222-227 (1993).

The applicability of these studies to Hanford Site waste thermal treatment and vitrification is very high. The papers deal with general vitrification performance, use of nontransferred plasma melters (such as the unit tested at the Westinghouse Science and Technology Center in Waltz Mill, PA for waste calcination and vitrification tests), behavior of cesium in vitrification, vitrification of sodium nitrate wastes, and the cold crucible technique and apparatus. 


\subsubsection{Provision of a Liquid Scintillation Counter}

During the visit to the IPC/RAS, scientists petitioned that a liquid scintillation counter (LSC) be provided by the DOE. Similar arguments had been made in talks as early as March 1994 when Professor Peretrukhin visited Hanford. With an LSC, more accurate analytical results and lower detection limits could be obtained for the DOE-funded studies. Without the LSC, cumbersome and error-inducing steps (neutralization, carrier precipitation, and acid dissolution) are required prior to preparation of classical planchet mounts. These steps are required to separate actinides and technetium from the high sodium matrices implicit in the Hanford Site tank waste experiments. With an LSC, no separations are required prior to simple introduction of aliquots of the test solutions into scintillation cocktail for counting in the LSC. The LSC also has higher sensitivity (lower background) which reduces the detection limit. Enhanced sensitivity is particularly important for studies of ${ }^{237} \mathrm{~Np}$ and ${ }^{99} \mathrm{Tc}$ which have low specific activities.

It was recognized that substantial customs fees could be imposed to import a LSC into Russia. Fees generally are 100 percent of the base price of the item. However, the IPC/RAS has a Shimadzu spectrophotometer supplied to the IPC under a French research contract. Import and customs fees were waived in that case by certification that the instrument would not be resold nor would it be used in a for-profit activity. Therefore it is likely that, just as in the case of the spectrophotometer, the LSC could be imported duty-free.

IPC/RAS scientists have proposed a candidate vendor for the LSC. The vendor is Wallac Oy, a Finnish firm that is a subsidiary of EG\&G, and which has an office in Moscow. The presence of the the vendor in Moscow is advantageous for acquisition, delivery, and service. Wallac $\mathrm{Oy}^{1}$ offers two instrument models that would be suitable for the IPC/RAS. The model $1415 \mathrm{DSA}^{\mathrm{TM}}$ is a benchtop instrument while the Quantulus $1220^{\mathrm{TM}}$ is console-sized. The instruments are compared below:

1415

1220

$$
\begin{gathered}
{ }^{14} \mathrm{C} \text { bkg. (CPM) } \\
2.0
\end{gathered}
$$$$
0.5
$$

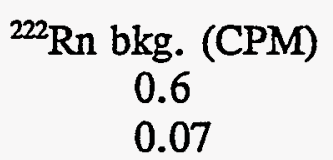

0.07
Est. Price (\$) 50,000 80,000

The ${ }^{14} \mathrm{C}$ performance roughly indicates the sensitivity for ${ }^{99} \mathrm{Tc}$ (both are $\beta$-emitters); the ${ }^{222} \mathrm{Rn}$ performance indicates the sensitivity for ${ }^{237} \mathrm{~Np},{ }^{239,240} \mathrm{Pu}$, and ${ }^{241} \mathrm{Am}$ (all $\alpha$-emitters).

${ }^{1} 1415$ DSA and Quarterlies are trademarks of Wallac Oy, Turku, Finland. 


\subsection{PROPOSED FISCAL YEAR 1996 WORK AT THE INSTITUTE OF PHYSICAL CHEMISTRY/RUSSIAN ACADEMY OF SCIENCE}

Eight proposals were made by the IPC/RAS for work in FY 1996. The eight proposals, as well as the names of the laboratory heads and lead scientists involved, were given during the program review. They are listed as follows.

- Investigate homogenous and heterogeneous catalysis (Krot/Shilov)

- $\quad$ to destroy organic compounds in waste

- $\quad$ to stabilize Np in the (IV) state.

- Investigate the effects of waste anions (for example, nitrate, nitrite, and others) on the removal of actinides from solution by the method of appearing reagents and determine the behaviors of ${ }^{90} \mathrm{Sr}$ and ${ }^{137} \mathrm{Cs}$ in these reactions. (Krot/Bessonov)

- Investigate disproportionation of Pu(V). (Krot/Budantseva)

- Investigate sorbents for $\mathrm{Np}, \mathrm{Pu}, \mathrm{Am}$ prepared from $\mathrm{La}$ and $\mathrm{U}$ hydroxides with inert carriers. (Krot/Tananaev)

- Investigate isolation methods for Tc (anion exchange, extraction, coprecipitation, cementation on metals, electrodeposition). (Peretrukhin)

- Investigate Tc response to thermochemical processing (calcination). (Kryutchkov)

- Investigate electrochemical denitration of waste in the presence of $\mathrm{U}, \mathrm{Np}, \mathrm{Pu}$, Tc, chromate. (Peretrukhin)

- Investigate alpha radiolysis in alkaline and alkaline/carbonate media. (Pikaev)

More complete descriptions of the eight proposals will be supplied by the IPC/RAS early in FY 1996 for further consideration by the DOE and WHC. 
WHC-SP-1166

This page intentionally left blank. 


\section{WHC-SP-1166}

\subsection{ACKNOWLEDGEMENTS}

The author is deeply indebted to Bette Lauzon, Rebecca Conner, Gene Wattenburger, Penny Gregory, and Sylvia Harlow of Multimedia Services for their tireless and painstaking work in preparing the technical literature review (Peretrukhin et al. 1995a) for publication. 
WHC-SP-1166

This page intentionally left blank. 


\subsection{REFERENCES}

Delegard, C. H., 1985, Solubility of $\mathrm{PuO}_{2} \cdot \mathrm{xH}_{2} \mathrm{O}$ in Alkaline Hanford High-Level Waste Solution, RHO-RE-SA-75 P, Rockwell Hanford Operations, Richland, Washington. Also, Radiochimica Acta 41, 11-21, (1987), same title and author.

Delegard, C. H., T. D. Elcan, and B. E. Hey, 1994a, Chemistry of Application of Calcination/Dissolution to the Hanford Tank Waste Inventory, WHC-EP-0766, Westinghouse Hanford Company, Richland, Washington.

Delegard, C. H., 1995a, Calcination/Dissolution Chemistry Development: FY 1995, WHC-EP-0882, Westinghouse Hanford Company, Richland, Washington.

Delegard, C. H., 1995b, Chemistry of Proposed Calcination/Dissolution Processing of Hanford Site Tank Wastes, WHC-EP-0832, Westinghouse Hanford Company, Richland, Washington.

Delegard, C. H., 1995c, Origin, Composition, and Treatment of Hanford Site Tank Wastes, WHC-SA-2920-VA, Westinghouse Fanford Company, Richland, Washington.

Peretrukhin, V. F. (Institute of Physical Chemistry, Russian Academy of Science) and C. H. Delegard (Westinghouse Hanford Company), 1995, Studies of the Chemistry of Transuranium Elements and Technetium at the Institute of Physical Chemistry, Russian Academy of Science, Supported by the U.S. Department of Energy, WHC-SA-2588-FP, Westinghouse Hanford Company, Richland, Washington.

Peretrukhin, V. F., V. P. Shilov, and A. K. Pikaev, 1995a, Alkaline Chemistry of Transuranium Elements and Technetium and the Treatment of Alkaline Radioactive Wastes, WHC-EP-0817, Westinghouse Hanford Company, Richland, Washington.

Peretrukhin, V. F., I. G. Tananaev, S. V. Kryutchkov, and V. I. Silin (Institute of Physical Chemistry, Russian Academy of Science), and C. H. Delegard (Westinghouse Hanford Company), 1995b, Solubility of Transuranium Elements and Technetium Hydroxide Compounds in NaOH Solutions in the Presence of Redox and Complexing Agents, WHC-SA-2921-A, Westinghouse Hanford Company, Richland; Washington. 
WHC-SP-1166

This page intentionally left blank. 


\section{DISTRIBUTION}

Number of Copies

QFFSITE

1

United States Department of Energy 12800 Middlebrook Road

Trevion II Building

Germantown, MD 20874

T. Fryberger

1

Qak Ridge National Laboratory

P. O. Box 2008

Oak Ridge, TN 37831-6178

J. S. Watson

\section{ONSITE}

1

MACTEC

D. J. Swanberg

K8-50

2

Pacific Northwest Laboratory

W. L. Kuhn (2)

$i^{\mathrm{K} 2-21}$

3

U.S. Department of Energy

Richland Field Office

R. F. Christensen

K8-50

B. A. Mauss

$\mathrm{K} 8-50$

S. N. Runyon

$\mathrm{K} 8-50$ 
H. Babad

S7-15

R. A. Bechtold

LO-18

J. D. Berger

LO-18

K. D. Boomer

H5-49

C. H. Delegard (5)

T6-09

D. W. Hendrickson

L5-31

J. R. Jewett

T6-09

S. L. Lambert.

H5-27

G. T. MacLean

H5-49

C. T. Narquis

T6-16

J. P. Sloughter

R2-54

OSTI (2)

L8-07

Central Files

L8-04

Document Processing and Distribution

A4-18 